\title{
Conf- $720676-1$
}

The Influence of $\mathrm{Cl}$ imatological Fluctuations on

Insect Populations in South-Central Washington

I. The Darkling Beetle Philolithus densicoll is (Horn)

(Coleoptera: Tenebrionidae)

W. T. Hinds and W. H. Rickard

Ecosystems Department

Battelle

Pacific Northwest Laboratories

Richland, Washington 99352

Apri1, 1972.

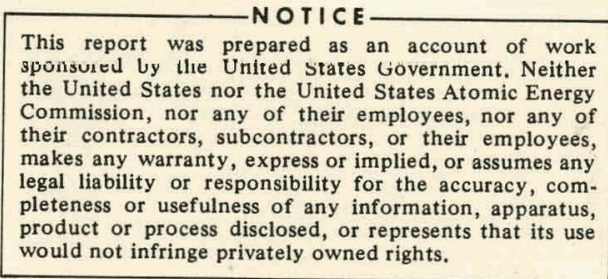

would not infringe privately owned rights. 


\section{DISCLAIMER}

This report was prepared as an account of work sponsored by an agency of the United States Government. Neither the United States Government nor any agency Thereof, nor any of their employees, makes any warranty, express or implied, or assumes any legal liability or responsibility for the accuracy, completeness, or usefulness of any information, apparatus, product, or process disclosed, or represents that its use would not infringe privately owned rights. Reference herein to any specific commercial product, process, or service by trade name, trademark, manufacturer, or otherwise does not necessarily constitute or imply its endorsement, recommendation, or favoring by the United States Government or any agency thereof. The views and opinions of authors expressed herein do not necessarily state or reflect those of the United States Government or any agency thereof. 


\section{DISCLAIMER}

Portions of this document may be illegible in electronic image products. Images are produced from the best available original document. 


\section{INTRODUCTION}

Ground-dwelling tenebrionid beetles form an obvious and important fraction of the fauna of the semi-arid regions of Washington, because at least on occasion, their numbers are large. In some cases, their biomass

is of the order of $20 \mathrm{~kg} \mathrm{ha}^{-1}$, about an order of magnitude greater than that attained by vertebrate herbivores (Rickard et al., in press). The species of interest here, Philolithus densicollis (Horn), is found in adult form only in early to middle autumn, making their emergence a notable phenological event in the seasonal progressions of the desert. During their brief emergence, the adults are readily taken by carnivorous animals; particularly interesting is the field observations that coyote (Canis latrans) scats during this period are sometimes entirely beetle exoskeletons. The adults are herbivorous during their surface life, but apparently are not obliged to eat to live. When numerous, these beetles may be by far the most influential grazer to which undisturbed desert vegetation is subjected (Rickard et al.; in press; Dickinson et al., in press).

Populations of these beetles are not constant. Pitfall traps exposed during the autumn emergence of the beetles since 1963 have collected progressively fewer until a minor resurgence in 1970: the total annual catch declined essentially monotonically from 1800 in 1963 to 60 in 1269 . (Fig. 1) A persistent decline in numbers such as this is quite a different thing than "crashes" in populations occurring from one year to the next. Crashes 


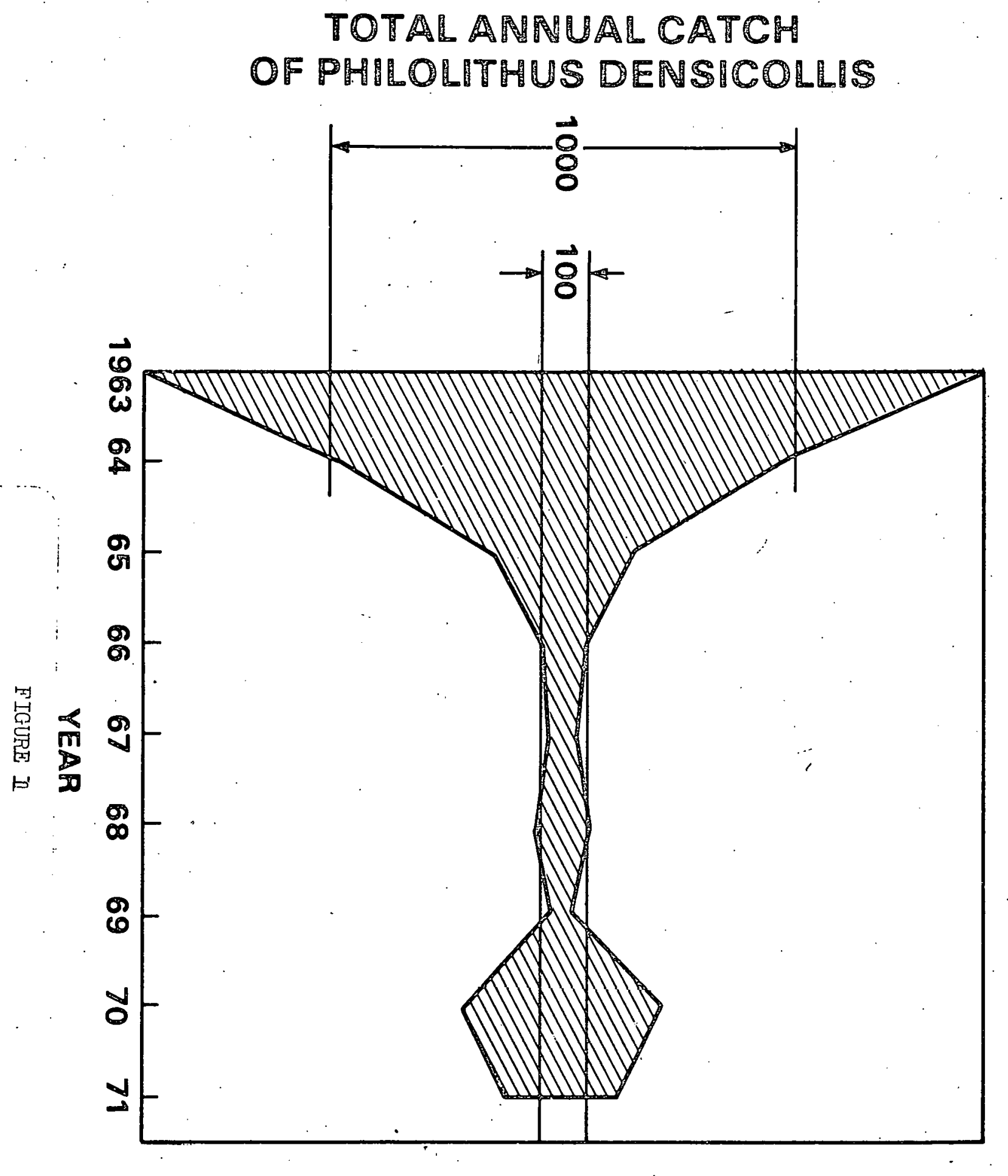


can quite often be accounted for by considerations of peculiarly unfavorable climatic conditions (c.f. Milne et al., 1965), but a continuous decline might be attributable to many readily conceived biotic mechanisms, rather than climatological variation. The purpose of the investigation reported here was to determine in fact how much or little pertinent weather conditions related to the observed decline.

The relatively sparse information concerning the life history of these beetles is outlined in a following section. The strategy of the investigation was to use the available information to formulate several hypotheses regarding possible or probable points where climatic fluctuations might impinge upon the beetles' life cycle, then examine the evidence concerning the hypotheses using available weather data and multivariate analytical techniques. The immediate temptation to clap many meteorological dáta into a multiple regression was resisted to the best of our ability. Rather, the climatological data were first screened by application of an old ecological axiom: the reproductive phase of an organism is more susceptible to interference than other phases. The surviving climatological data were collected into a data matrix that was then decomposed into principal components for correlation with the pitfall dald. The purpose of this step was to illuminate patterns in relations between climate and trapping data, as opposed to simple correlations such as result from linear regressions. The third step was to use any insights from the principal component analysis tc provide sensible criteria for selecting variables as input to a multiple regression model of the observed population dynamics. As will be discussed in the concluding section, this approach allowed firmer interpretation of some of the observed correlations. This approach was successful for P. densicollis, but another tenebrionid Stenomorphá puncticoll is (LeConte), which 
has a closely similar life history and phenology, was not so amenable, as will be shown in a later paper. The model is in fact correlative, not mechanistic,

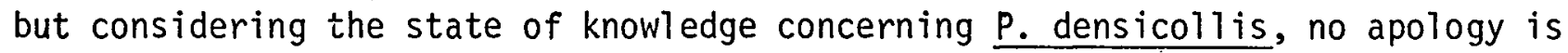
necessary.

The paper begins with a description of the study sitc and the life history of the beetles, followed by the several hypotheses generated from consideration of the life history. The methods employed, both in the field and at the computer console, and the data are then presented. Resuits are discussed in two sections, the principal component analysis and the regression analysis. Some obvious ecological interpretations are then presented, along with their implications for further study, in the concluding section.

\section{THE SITE}

The study site was a stand of sagebrush (Artemisia tridentata) on the $300 \mathrm{~km}^{2}$ Arid Lands Ecology Reserve; an area set aside for ecological studies by the United States Atomic Energy Commission from its Hanford Reservation in South-central Washington.

The climate is decidedly deficient in rainfall, with an annual average of 6.3 inches ( 16 centimeters). About two-thirds of the precipitation falls between October and May--half as snow--and provides a store of soil moisture for a spring growing season. Winters are cold, but not extreme, as temperatures below $0^{\circ} \mathrm{F}\left(-18^{\circ} \mathrm{C}\right)$ are expected only every other year or so. Summers are hot and dry, so soil moisture declines steadily from a maximum in early March to its. minimum in September, when the surface decimeter contains only one or two percent moisture. 
The soil is a silt loam by texture. It is a young soil, formed from lake-laid deposits from a post-glacial lake behind temporary ice jams, about ten or twelve thousand years ago. The surface meter is essentially stonefree, with near neutral pH. Alkalinity increases somewhat with depth, and a calcareous subsoil usually occurs about a meter deep. Otherwise, the profile is not well developed.

The vegetation is dominated by big sagebrush (Artemisia tridentata), with a sparse understory of perennial nerbs, principally Sandberg bluegrass (Poa sandbergii), a small bunch grass. Annuals are scarce. Cheatgrass (Bromus tectorum), the common invader of disturbed soil in this region, is sparingly represented on the site, indicative of relatively undisturbed conditions (Daubenmire, 1970). Figure 2 shows the general aspect of the site and surroundings.

\section{THE BEETLES}

Hitherto, these species have been little studied, and the literature concerning them is primariiy taxonomic. A recent taxonomic treatment of Philolithus densicollis discussed its relation to other tenebrionid genera, pointing out that its previously accepted ascription to the genus Pelecyphorus was in error (Brown, 1971). Thus, earlier ecological works naming Pelecyphorus densicollis refer to the taxon Philolithus densicoll is (Rickard anc Haverfield, 1963; Rickard, 1970a; Rickard, 1970b; Al1red et $\underline{\text { al }}, 1963)$. 


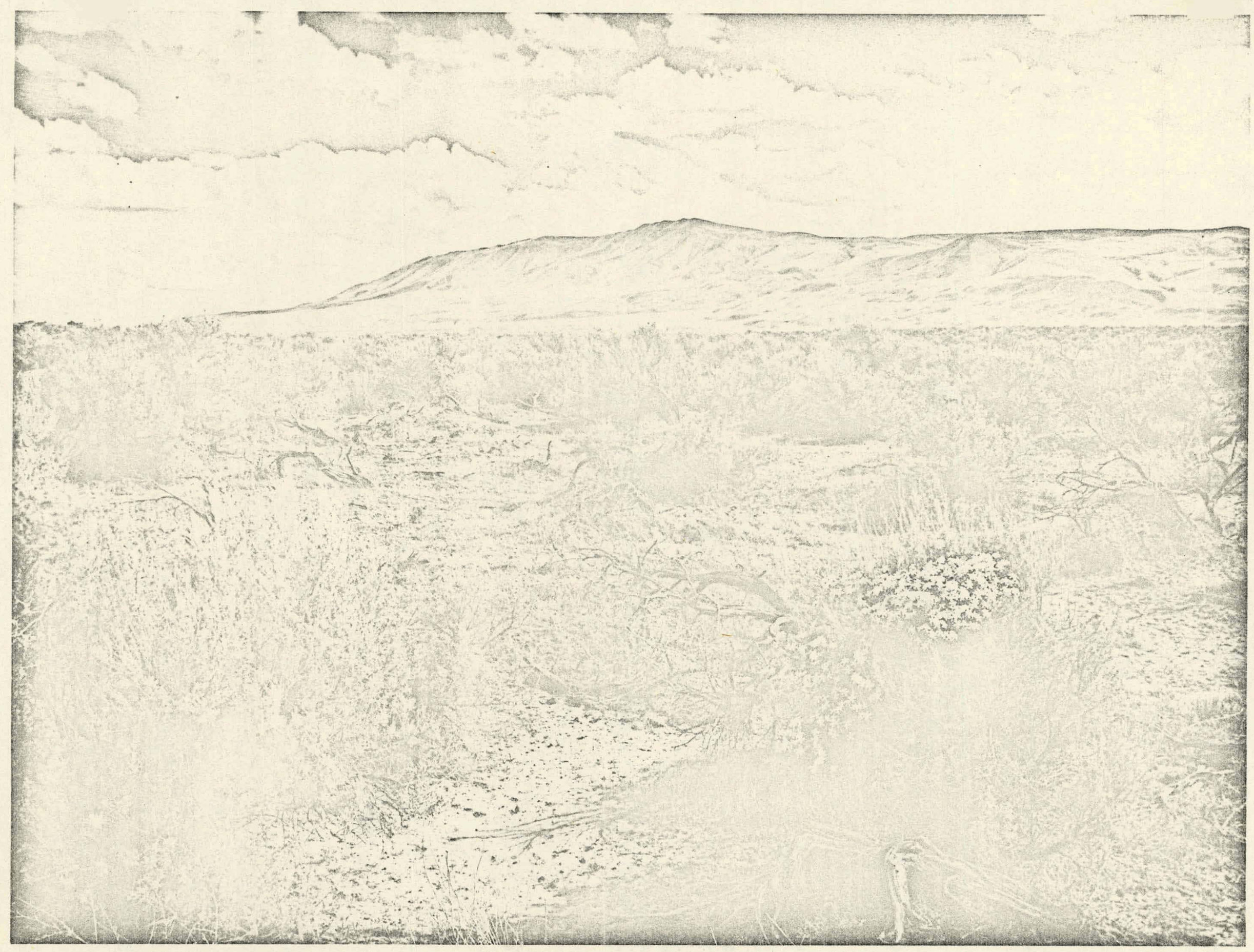


Most of the knowledge concerning the life history of this beetle has been provided by Kirby W. Brown; Curatorial Associate of Entomology, Peabody Museum, New Haven, Connecticut. The following paragraphs are a distillation of the laboratory and field observations he has generously provided is, along with a few personal observations.

Adults eclose in late summer and early. autumn, for a brief life span--about a month in the laboratory. The adults are herbivorous, but there is iothing to suggest they must feed to 1 ive or reproduce, because unfed adults in the laboratory survived about as long as those provided food. The adults tend to be daytime active, expecially when the nights grow cold. Oviposition habits in the field are not well understood; from limited laboratory observations, Brown assumes the beetle oviposit perhaps a single egg each day. The eggs are relatively large--about $20 \%$ the body length of the adult female, and are deposited about a centimeter below the soil surface. A sclerotized ovipositor acts as, a drill, so hard, dry soil is no deterrent to oviposition, although moist microsites are apparently preferred.

In the laboratory, Philolithus eggs hatch in one to two weeks. The first instar is an inactive grub, quickly changing to second instar. The larvae are unusual for tenebrionids, being pale, unsclerotized, readily dehydrated, and generaliy poorly adapted for life on the surface. By. contrast, the larvae have well developed, scoop-shaped mandibles and enlarged forelegs, providing means for easy movement through the soil. The larvae select ingestible material through their travels, and apparently 
are scavengers (except for cannibalistic behavior), for no. living plant material was necessary for successful laboratory rearing. The larvae do not surface after hatch until eclosure as adults.

The length of the life cycle of these beetles is not available, as study terminated in the early instars. Closely related tenebrionids require two months at temperatures less than $10^{\circ} \mathrm{C}$ to break diapause in late instars and induce pupation, usually completing their cycle in less than two years, but more than one year, in the laboratory.

'HYPOTHESES AND STATEMENTS FOR STUDY

The life history information summarized above presents sufficient detail to allow specific questions concerning the supposed relation between beetle populations and climate. These questions were phrased before the computation began, practically in textbook fashion, as follows :

1) Null hypothesis: There is no relation between pitfall trapping success and climatic variables during the reproductive phase of the beetles' 1 ife cycle.

2) Nul1 hypothesis: The climatic variables of importance are those in the year of trapping, indicating activity rather than abundance.

3) Null hypothesis: Pitfall trapping success is independent of 
total cool-season precipitation (the principal determinant of vegetation productivity).

4) Question for study: What evidence is there to specify whether the beetles' life cycle is of one year or two years duration?

THE DATA

The appropriate data clearly should be related to soil surface conditions during the period of adult emergence, oviposition and hatch. Monthly averages of soil surface temperatures and precipitation seemed most appropriate as the independent variables, because the life span of the beetles, and the length of each phase of the reproductive cycle, are approximately a month. Since interest centered or population variation between years, the total number of beetles trapped during a given year seemed best as the dependent variable.

The climatic data were taken from data gathered by the Atmospheric Sciences Dept. at a station some six miles from the study site. The meteorological station is located on soil very similar to that at the study site (Hajek, 1966), supporting vegetation that is likewise very similar. Air temperatures, precipitation and albedo are similar at both sites, also, (Hinds and Thorp, 1968, 1971; Hinds, unpublished) so the soil temperatures at both must be similar. The temperature at $1.25 \mathrm{~cm}(0.5$ in) was selected as being representative for both adult activity and egg and early instar environments. The temperatures were averaged over daylight 
and darkness periods seperately, to accord with the daytime activity tendency of the species. Precipitation at the study site was closely correlated with precipitation at the meteorological station, (Hinds and Thorp, 1971), and monthly totals were taken directly from the meteorological records. Table 1 presents the data.

\section{METHODS EMPLOYED}

Estimates of beetle abundance were made by pitfall traps, maintained in the same plant community and visited weekly during the autumn, for nine consecutive years. Forty nine pitfalls were arranged in a $7 \times 7$ grid pattern with three meter spacing between traps. The traps consisted of metal cans $10 \mathrm{~cm}$ in diameter and $25 \mathrm{~cm}$ deep buried in the ground until the rim was flush with the surrounding soil surface. The pitfalls were capped at the end of the beetle emergence in late November or early December, and not visited again until the following September. A11 beetles were released alive at their place of capture. Although beetles were confined to the traps for up to a week, mortality in the traps was insignificant.

Pitfall traps have had several drawbacks attributed to them, particularly for quantitative population studies, so it is appropriate to consider whether these drawbacks apply to this study. The general conclusion will be that the: do not apply.

Pitfall traps confound abundance and activity, because an increase in either increases probability of capture. There is little hope of 
separating these two components of capture probability a priori, so this problem was set up as a null hypothes is for examination.

Behavioral changes in the population at risk may cause serious errors in pitfali trapping success. Behavioral changes must ordinarily be expected between instars (Gilbert, 1958). However, behavior should indeed be constant within species between generations. Using total annual catch as samples of succeeding generations of univoltine insects as the population at risk should keep behavioral changes miniscule.

Trapping efficiency apparently changes with soil moisture under laboratory conditions, but caused undetectable changes in field conditions (Mitche11, 1963). Soil moisture varied strongly throughout the season in our study, but soil moisture trends between years are relatively constant on the site, being quite dry in September and quite moist in December. So, no between-year bias can be expected.

Different species are trapped in differing proportions (Greenslade, 1964) primarily because of behavioral aspects of activity in relation to surface cover density. Maintaining the traps at the same site for sever:al year's relluved thls problem, under the simple and realistic assumption that the relative proportion trapped remained constant between years except insofar as enviionmentally controlled activity reponses were concerned. Pitfall trapping provides information of relative population sizes without information on total population size. Problems of trapping constancy between habitats were nonexistent, because the traps remained in one habitat. 
Considering all the above, it seems likely that pitfall trapping was approximately equaliy efficient between years except insofar as temperature might alter activity, the null hypothesis mentioned earlier.

The pitfall trapping data were counts and required some sort of transformation to possess a constant variance.' We chose a square root transformation of the pitfall data, a common approach for count data (Bliss, 1967). Ordinarily, population analyses use a logarithmic transformation because of the geometric nature of population changes (Morris, 1960) and because of an assumed multiplicative nature of variables (Mitche11, 1963). These considerations are most applicable to population variation within years for multivoltine insects, and are less appropriate for considerations of abundance of univoltine insects between years because any climatological stresses feaucing the population tend to be density independent (Thompson, 1956). We therefore chose to use the climatic data in untransformed condition, assuming a linear relation between vears.

Multivariate methods offerred the most efficient analysis of the data. However, simply exploring the many dimensions of possible regression models is intellectually unsavory without some rational basis for choosing variables (Watt, 1962). To aid in setting criteria for variable selection, we subjected the climatic data to a principal component analysis, then used the components as independent variables in a regression analysis with the pitfall data. The rationale and implications of this approach deserve some amplification. 
Principal components are mutally uncorrelated linear combinations of the independent data which in sum reproduce most of the variance in the original data (Morrison, 1967). Data with disparate dimensions, such as we have here (degrees Fahrenheit, inches of precipitation) suggest that the correlation matrix, calculaied from the variance-covariance matrix of the original data, would provide the most reasonable starting point. In the correlation matrix, all data variability has been reduced to standard scores in the range -1 to $i$.

The first principal component (eigenvector) is that linear combination of the correlations that accounts for the maximum amount of variability in the correlation matrix. The second principal component is that linear combination of the correlations which accounts for the next largest proportion of variability in the correlation matrix, subject to the constraint that the second component must be completely uncorrelated with the first... not overlapping in "explained" variability. This procedure may be continued until a satisfactory proportion of the total variability in the correlation matrix has been attributed to the several (or few) principal components. The advantage to this procedure is that the variability in our $18 \times 18$ climatic data correlation matrix can be reproduced within $2 \%$ with only seven components, each of which represents an individual pactern of variability within the climatic data. Thus, instead of 18 variables with correlations among themselves, only seven variables remain, havirig no correlation with each other, each representing a pattern of climatic occurrences. 
The relation between the principal components and the pitfall data was determined by applying multiple regression techniques to the principal components and the pitfall trapping data. In this fashion, the components best correlated with the pitfall data were found and examined for their characieristics in terms of climatic variables. This step illuminated patterns of climatic interactions with populations, allowing a more reasonable approach to otherwise rather arbitrary selections of variables for multiple regression analysis. To be sure, the original selection of climatic variables for the principal component analysis itself was guided only by Brown's life history information, the ecological principal that reproductive phases of organisms's lives tend to be easiest to disrupt, and intuition.

In the final analysis, the principal component analysis and multiple regressions contain the same information, so this approach does not in fact increase the total information relating populations to environment. However, principal components often lend themselves to interpretation, due to dominance within a component of a few variables. The advantages, if any, devolve from the independent nature of the combinations in each principal component... such independence is by no means either necessary (Mead, 1971) nor common in independent variables for regression analyses.

The search for relationships between climate and populations described here bears more than a passing resemblance to modern dendrochronological analys is (c.f. Frit.ts, et. al, 1971). In both cases, the rationale for interaction between climate and population indices already existed (Fritts, 
1970; Solomon, 1957; Thompson, 1956), so the multivariate techniques were employed to optimize the picking and choosing amongst competing variables, and quantify the basis for choice.

\section{RESULTS FROM PRINCIPAL COMPONENT ANALYSES}

Seven components were found associated with $98 \%$ of the variance in the climatological daia. The components were characterized according to the fewest variables providing $50 \%$ or more of the total weights of the component (that is, the fewest variables whose weighting contributed to half or more of the eigenvalue of the component). The average weighting of the "dominant" variables was about 12\% each, whereas the remainder were weighted about $3 \%$ each. In the following discussion, the less important contributors to each component will be ignored.

Each component has a specific value for each specific combination of climatic data (that is, each year). These values for each year were used as independent variables in a stepwise regression of pitfall data on climate, with the results summarized in Table II. The characteristics (or patterns) of the components are displayed in Figure 3 , with the components found to be related to the pitfall data separated from the components uncorrelated with the pitfall data. From Table II, it is clear that the components most closely tied to the pitfall data are those accouriting for the least of the clinatic variability. This must imply that much of the variability in climate has little bearing on. pitfall trapping success, and may imply that specific climatic variables 

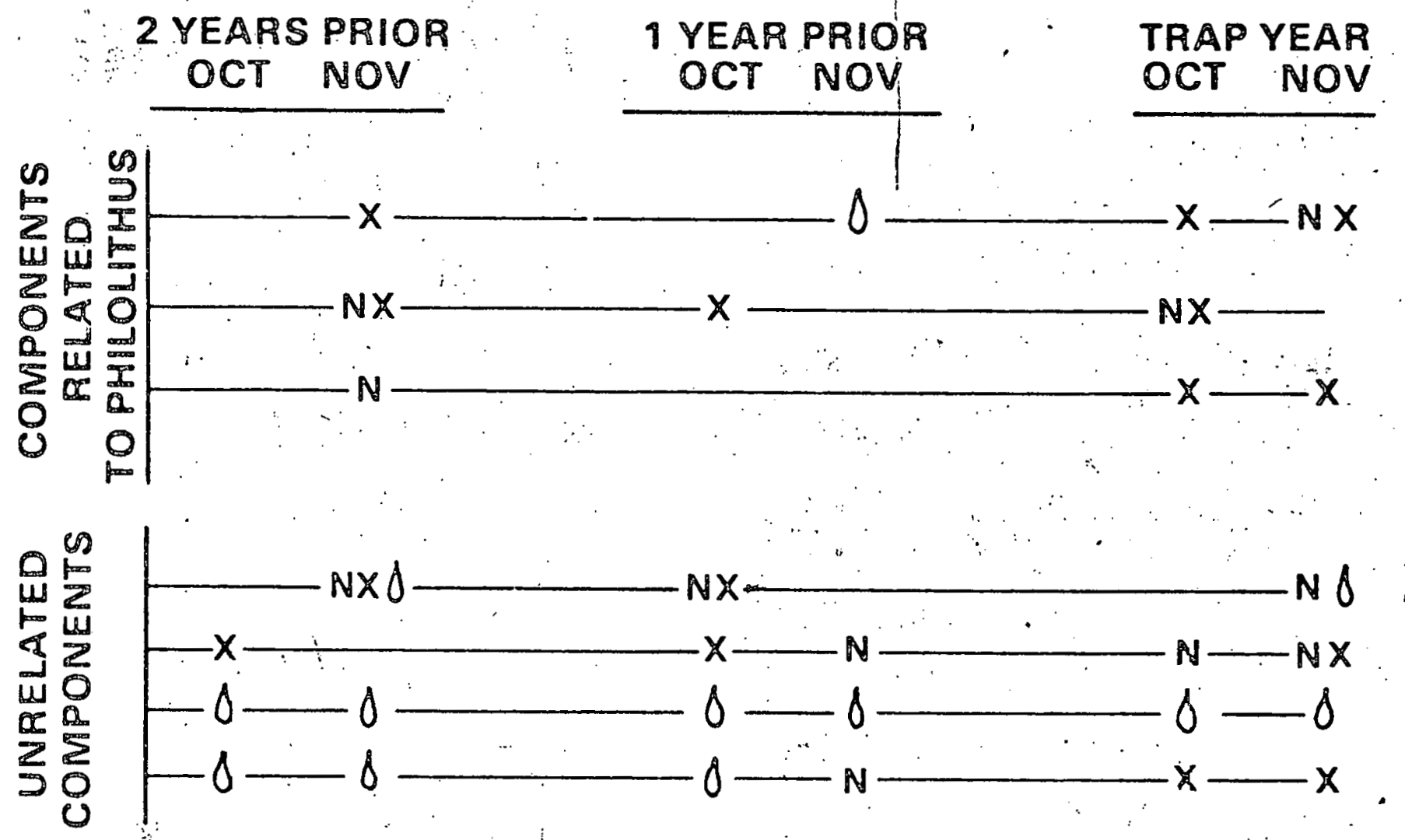

O PRECIPITATION

$X$ MAXIMUM

TEMPERATURE

FIGURE 3
N MINIRUM

TEMPERATURE 
are individually responsible for the variability in trapping data. Note, too, that the high degree of variance accounted for by these three components indicates that climatic fluctuations must indeed be closely related with the pitfall data.

Figure 3 bears examination. The three components separated on the top half of the figure are those entering the regression equation. Note especially the paucity of influence of climatic data from one year before trapping. This can only mean that clinatic variables observed one year before eclosure have very little relation to pitfall data, and therefore provides substantial evidence that the larvae reside in the soil two seasons, an answer to the question posed earlier.

A further point emerges from Figure 3 . The pitfall data have very little relation to precipitation factors in the components. Only a single precipitation datum enters the components related to pitfall data, and that is in the year prior to trapping. Apparently precipitation is not an importantly limiting factor, for one of the components that is not related to the pitfall data contains nothing but precipitation variables in its makeup.

\section{RESULTS FROM REGRESSION ON CLIMATIC VARIABLES}

As mentioned earlier, each principal component contains a contribution from each of the input climatic variables. Even though to this point each component has been characterized by the dominant few climatic variables in its makeup, still the reality is that the components discussed in the 
previous section contain a considerable "noise" from the remaining climatic variables in addition to the relatively clearcut contributions from the dominants. However, the patterns from the principal components' regression provide a criterion for selection of specific climatic variables to be used as independent variables in a regression analysis: the data shouid come only from the year of trapping and two years prior to trapping.

The results of the stepwise regression are summarized in Table III, and the relative success of the resulting model in reproducing the observed population decline is shown in Figure 4, from the equation

$$
N^{1 / 2}=18.23+14.750_{2} P+1.4780 T_{x}-3.476 N_{2} T_{n} .
$$

Examination of Table III and Figure 4 shows cieariy that a very high proportion of the total variance of the pitfall trapping data is associated with specific climatic parameters, and that most of the variance accounted for is from two years before trapping $(64 \%)$. In contrast, the variance related to the year of trapping is $26 \%$, and unexplained variance is $10 \%$. The clear implication is that nearly two-thirds of the observed decline in pitfall trapping success is related to climatic variations during adult emergence and reproduction, and about one quarter is due to changes in activity of the bectles between years. 


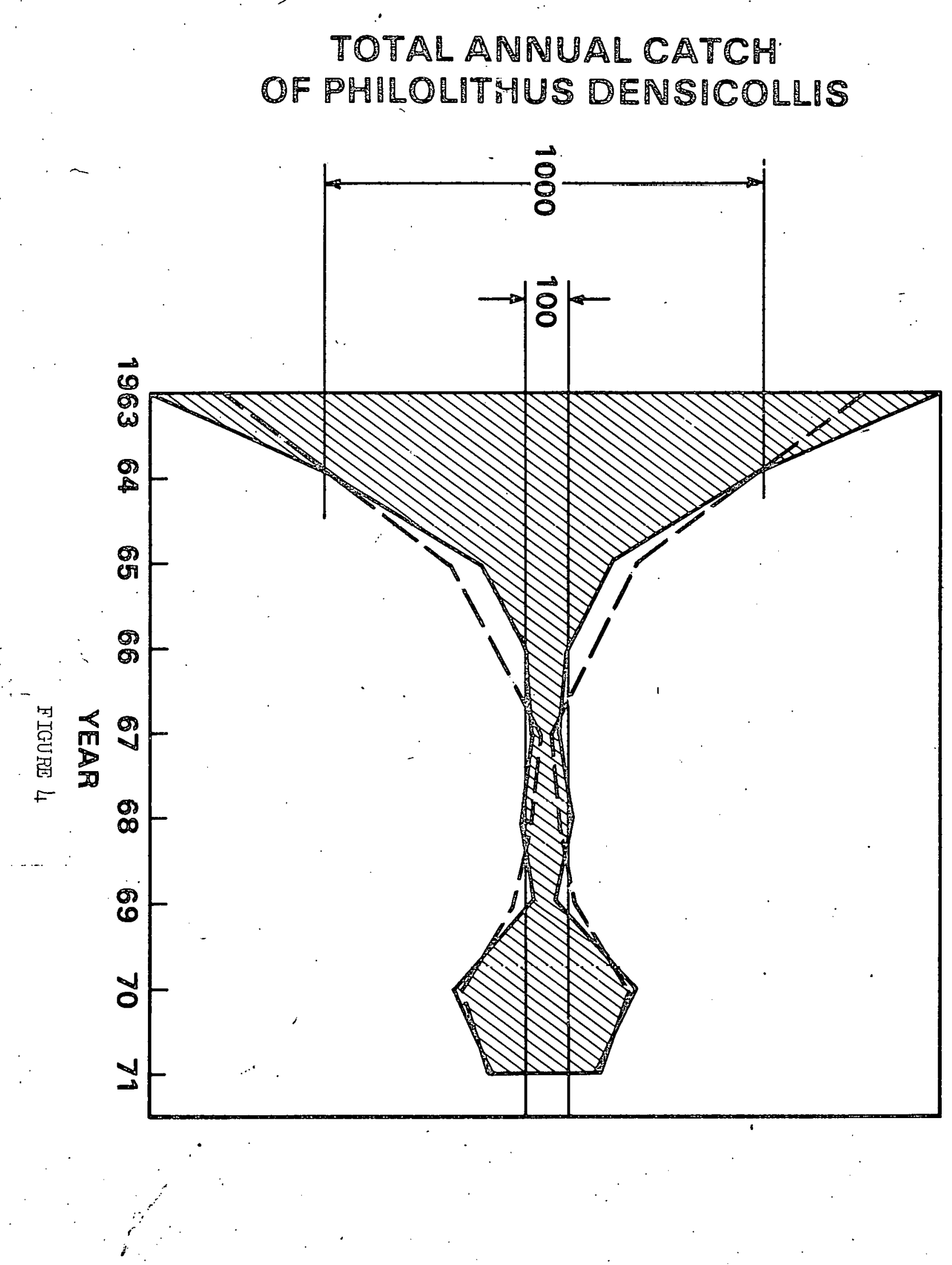




\section{DISCUSSION}

There exist several mechanisms which could conceivably act to reduce the total catch of the beetles but have not been considered before, such as predation or chemical pesticide drift from agricultural fields. The potential significance of some of the more pertinent of these will be assessed here.

Pesticide Drift: The study site is well insulated from surrounding activity of all sorts, buffered by several miles of reserved lands in all directions. The nearest agricultural lands are dryland wheat fields six miles upwind and 2500 feet higher in elevation. The potential for drift over this distance is nil, due to restrictions on pesticide applications during windy conditions.

Predation: Little is known quantitatively concerning predation of the adult beetles, beyond the observations that they may be readily taken by coyotes, and probably gallinácenus birds. Predation by other arthropods is probably slight, because only Black Widow spiders are known to be able to kill the adults. Carabid beetles (Calosoma $\mathrm{sp}$ ) are spring emergents in this region and may prey upon larvae. Nothing is known concerning predation upon the larvae, either at the time of hatch or during their resiuence in the soil. 
Fire, Grazing and Other Surface Disturbance: The study site has been little disturbed in any manner. Grazing apparently was never a strong disturbance at this site, due to the rather sparse understory growth; in any case, grazing was completely eliminated (for domestic species) in 1960, when the immediately surrounding 800 acres were fenced in. The study site has not been burned for probably a hundred years at least, as evidenced by long dead (and readily ignited) stubs and branches of sagebrush at the site. The oldest living sagebrush in the area probably approach 70 years. of age, based on ring-counts in similar sites. Other surface disturbance has been nil, and in any case, the presence of P. densicollis has been shown to be independent of fire (Rickard, 1970b) and differing vegetation types (Rickard, 1970a).

Clearly, the general decline in catch is satisfactorily accounted for by recourse to climatic variation alone, and specifically, to only three climatic factors. At this point, it is salutory to remind one another that although the "explained" variance in labie ill is high, still we have a correlative model rather than a mechanistic model... we may only say, for example, that moist 0ctobers two years ago tend to increase pitfall trapping success this year, and so on. There is no evidence for specific biotic mechanisms, whether physiological or behavioral, that might account for the changes in abundance noted (and attributed to climatic variation). However, the relatively simple regression, and the high correlation, 
provide a tempting ground for speculation into specific mechanisms involved. We will more or less stoutly resist the temptation, and offer instead a few obvious conclusions.

First, the regression model requires rejection of the first null hypothesis. Secondly, the importance of climate in the year of trapping is restricted to October maximum temperatures, an indicator of activity. This variable accounts for only a quarter of the total variability, whereas variables during the second year prior account for nearly three times as much variability. Therefore, the second null hypothesis, that all the variability in pitfall trapping is due to changes in activity, must be rejected...at least part of the variability is due to true changes in abundance.

Third, the relative lack of importance of precipitation deduced from the principal component analysis is seen to apply only in general; specifically, October precipitation in the year of oviposition accounts for about $20 \%$ of the variability observed two years later. Apparently soil moisture has little to do with trapping efficiency, as noted earlier, but it is of considerable importance for reproduction.

However, a direct examination of the importance of total winter precipitation in the regression analysis indicated there was no correlation whatsoever with pitfall trapping success. Thus, the third null hypothesis, that the variability in trapping success was independent of precipitation, and therefore plant productivity, can not be rejected. This corroborates Browi's observations that the larvae are scavengers (decomposers) in the ecosystem, rather than herbivores. (consumers). 
The importance of November minimum temperatures is somewhat an enigma, even though it accounts for nearly half the total variability of trapping. Note that the relation is negative... warm November nights during reproduction are related to a decrease in trapping success two years later. There is no obvious ecological interpretation, but there is a wealth of speculative potential in this result. It seems likely that this would be a profitable point to begin research into the behavior and physiology of the beetle.

\section{CONCLUSIONS}

From the foregoing analysis, the following conclusions seem appropriate:

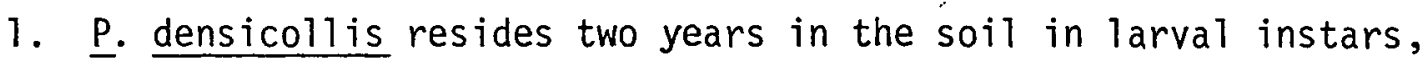
whose function in the ecosystem is as a decomposer rather than herbivore.

2. The obseived decline in pitfall trapping of Philolithus densicollis is due primarily to a real decline in abundance, 'rather than changes in activity:

3. The decline in abundance is primarily related to climatological variation, principally November minimum soil temperatures and October precipitation during oviposition of the generation to be trapped, and secondarily October maximum soil teinperatures in the year of trapping. About $90 \%$ of the variability in pitfall trapping is related to these three variables. 


\section{TABLE I}

\section{CLIMATIC AND PITFALL TRAPPING DATA}

\begin{tabular}{|c|c|c|c|c|c|c|c|c|}
\hline \multirow[b]{2}{*}{$\underline{\text { YEAR }}$} & \multicolumn{3}{|c|}{ OCTOBER } & \multicolumn{3}{|c|}{ NOVEMBER } & \multirow{2}{*}{$\begin{array}{l}\text { Total } \\
\text { Winter } \\
\text { precip } \\
\text { inches } \\
\end{array}$} & \multirow[b]{2}{*}{$\begin{array}{l}\text { Tot. Ann. } \\
\text { catch of } \\
\text { Philolithus }\end{array}$} \\
\hline & $\begin{array}{l}\text { precip } \\
\text { inches }\end{array}$ & $\begin{array}{l}\max T \\
{ }^{\circ} \mathrm{F} \\
\end{array}$ & $\begin{array}{l}\min T \\
{ }^{\circ} \mathrm{F} \\
\end{array}$ & $\begin{array}{l}\text { precip } \\
\text { inches }\end{array}$ & $\begin{array}{l}\max _{{ }^{\circ} \mathrm{F}} \\
\end{array}$ & $\min _{{ }^{\circ} \mathrm{F}} T$ & & \\
\hline 1961 & 0.07 & 83.7 & 41.6 & 0.49 & 56.9 & 28.3 & & \\
\hline 1962 & 0.95 & 79.5 & 43.3 & 0.65 & 57.4 & 35.8 & 4.00 & \\
\hline 1963 & 0.04 & 79.2 & 47.9 & 0.74 & 53.4 & 38.1 & & 1803 \\
\hline 1964 & 0.28 & 83.4 & 42.4 & 0.94 & 46.9 & 34.3 & & 918 \\
\hline 1965 & 0.01 & 90.7. & 45.9 & 1.17 & 56.1 & 38.7 & 2.75 & 297 \\
\hline 1966 & 0.39 & 75.5 & 45.1 & 2.25 & 55.2 & 38.3 & 5.76 & 101 \\
\hline 1967 & 0.13 & 80.6 & 46.0 & 0.16 & 57.5 & 34.0 & 2.27 & 62 \\
\hline 1968 & 0.93 & 78.6 & 42.7 & 1.23 & 53.8 & 36.3 & 7.02 & -120 \\
\hline 1969 & 0.10 & 74.2 & 41.2 & 0.13 & 51.9 & 34.3 & 6.00 & 58 \\
\hline 1970 & 0.24 & 77.1 & 38.4 & 0.71 & 50.5 & 32.2 & 4.09 & 427 \\
\hline 1971 & 0.18 & 79.0 & 39.5 & 0.46 & 50.7 & 32.5 & & 238 \\
\hline
\end{tabular}

NOTE: In the text, $0=$ october, $N=$ November, $P=$ precipitation, $T$ = temperature; subscript $2=$ two years before trapping subscript $1=$ one year before trapping subscript $x=$ maximum temperature subscript $n=$ minimum temperature 


\section{TABLE II}

PRINCIPAL COMPONENTS FOUND TO BE CORRELATED WITH PITFALL TRAPPING DATA

\begin{tabular}{|c|c|c|c|c|}
\hline $\begin{array}{l}\text { Step } \\
\text { No. }\end{array}$ & $\begin{array}{c}\text { Component } \\
\text { No. }\end{array}$ & $\begin{array}{l}\text { Associated } \\
\text { Climatic } \\
\text { Variance } \\
\end{array}$ & $\begin{array}{c}\text { Associated Increase of } \\
\text { Explained Variance of } \\
\text { Pitfall Data } \\
\end{array}$ & $\begin{array}{c}\text { Cumulative } \\
\text { Variance of Pitfall } \\
\text { Data Accounted for } \\
\left(R^{2}\right)\end{array}$ \\
\hline 1 & 6 & $8 \%$ & $52 \%$ & .52 \\
\hline 2 & 7 & $3 \%$ & $25 \%$ & .77 \\
\hline 3 & 3 & $15 \%$ & $14 \%$ & .91 \\
\hline
\end{tabular}




\section{TABLE III}

STEPWISE MULTIPLE REGRESSION OF PITFALL DATA ON CLIMATIC VARIABLES

\begin{tabular}{|c|c|c|c|c|c|c|}
\hline Step & Variable & $\begin{array}{l}\text { Increase in } \\
\text { Variance of } \\
\text { Pitfal Data } \\
\left(R^{2}\right) \\
\end{array}$ & Intercept & $\begin{array}{l}\text { Standard } \\
\text { Error of } \\
\text { Estimate }\end{array}$ & $\begin{array}{l}\text { Regression } \\
\text { Coefficient }\end{array}$ & $\begin{array}{c}\text { Standard } \\
\text { Error of } \\
\text { Coefficient }\end{array}$ \\
\hline 1 & $N_{2} T_{n}$ & .43 & & & -3.48 & .58 \\
\hline 2 & ${ }^{0} \mathrm{~T}_{\mathrm{x}}$ & .26 & & & 1.48 & .37 \\
\hline \multirow[t]{3}{*}{3} & $0_{2} P$ & .21 & ' & . & 14.75 & 4.68 \\
\hline & & & $\cdot$ & & $\cdot$ & \\
\hline & All & .90 & 18.23 & 4.78 & & \\
\hline
\end{tabular}




\section{REFERENCES}

Al1red, D. M., D. E. Beck, and C. D. Jorgensen, 1963: Biotic communities of the Nevada test site. Bringham Young University Sci. 'Bull. Biol. Ser. Vol. II, №. 2, p. 52.

Bliss, C. I., 1967: Statistics in Biology, Vol. I; McGraw-Hi11, New York, 567 p.

Brown, K. W., 1971: Redefinition of the genera Pelecyphorus and Philolithus with a key to the genera of the tribe Asidini (Coleoptera:Tenebrionidae) Coleopterists Bu1125: 17-30.

Daubenmire, R., 1970: Steppe Vegetation of Washington, Wash. Ag. Expt. Sta. Tech. Bu11. 62; Put iman, Washington.

Dickinson, C. E., T. D. Thatcher and M. K. Campion, in press: Statistical analysis and grouping of shortgrass prairie insect biomasses. Submitted to J. Range Mgmt., 1972 (IBP Grass7and Biome Preprint No. 32); Colo. State Univ., Fort Collins, Colorado.

Fritts, H. C., 1970: Tree ring analys is and reconstruction of past environments. U. British Columbia Faculty of Forestry, Bu17. No. 7, 92-98; Vancouver, B.C., Canada.

Fritts, H. C., T. J. Bỉasing, B. P. Hayden, and J. E. Kutzbach, 1971:

Multivariate techniques for specifying tree-growth and climate relationships and for reconstruction anomalies in paleoclimate. J. Appl. Meteor. 10:845-864.

Gilbert, 0., 1958: The 1 ife history patterns of Nebria degenerata Schaufuss and $\mathrm{N}$. brevicoll is (Fabricius) (Coleoptera; Carabida1). J. Soc. Brit. Ent. 6: $11-1 \overline{4}$.

Greenslade, P. J. M., 1964: Pitfall trapping as a method for studying populations of Carabidae (Coleoptera). J. Anim. Ecol. 33:301-310.

Hajek, B. F., 1966: Soil Survey, Hanford Project in Benton County, Washington. Bâttelie Memorial Institute, Paćific Northwest Laboratories, Report BNWL-243. $18 \mathrm{pp}$. Richland, Washington.

Hinds, W. T. and J. M. Thorp, 1969: Biotic and abiotic characteristics of the microcl imatological network on the Arid Lands Ecology Reserve. Battelle Memorial Institute, Pacific Northwest Laboratories, Report BNWL-SA-2733, 63 p: Richland, Washingtor.

Hinds, W. T. and J. M. Thorp, 1971: Annual summaries of microclimatological data from the Arid Lands Ecology Reserve: 1968 through 1970. Battelle Memorial Institute, Pacific Nor.thwest Laboratories, Report.BNWL-1629, 36 p. Richland, Washingtón. 
Mead, R., 1971: A note in the use and misuse of regression models in ecology. J. Ecol. 59:215-219.

Milne, A., R. Laughl in and R. E. Coggins, 1965: The 1955 and 1959 population crashes in the leatherjacket, Tipula paludosa Meigen, in Northumberland.

J. Anim. Ecol. 34:529-544.

Mitche11, B., 1963: The ecology of two Carabid beetles, Bembidion lampros (Herbst) and Trechus quadristriatus (Schrank), II: Studies on popuTations of adults in the field, with special reference to the technique of pitfall trapping. J. Aniin. Ecol. 32:377-392.

Morris, R. F. 1960: Sampling insect populations. Ann. Rev. Entomol. 5: 243-254. Morrison, D. F., 1967: Multivariate Statistical Methods. McGraw-Hill, New York.

Rickard, W. H., 1970a: The distribution of ground-dwelling beetles in relation to vegetation, season, and topography in the Rattlesnake Hills, southeastern Washington. Northwest Sci. 44:.107-113.

Rickard, W. H., 1970b: Ground-dwelling beetles in burned and unburned vegetation. J. Range Management 23:293-294.

Rickard, W. H., J. F. Cl ine and R. 0. Gilbert, in press: Autumnal emergence of darkling beetles in abandoned old fields. Submitted to 0ikos, 1972.

Rickard, W. H. and L. E. Haverfield, 1965: A pitfall trapping survey of darkling beetles in desert steppe vegetation. Ecol. 46: 873-875.

Snedecor, G. W. and W. G. Cochran, 1967: Statistical Methods. Iowa State Univ. Press, Ames, Iowa, 593 p.

Solomon, M. E., 1957: Dynamics of Insect Populations: Ann. Rev. Entom. 2: 121142.

'Thompson, W. R., 1956: The fundamental theory of matural and biological control. Ann. Rev. Entom. 1: 379-402.

Watt, K. E. F., 1962: Use of mathematics in population ecology. Ann Rev. Entom. 7: 243-260. 